\title{
Determinantes do Crédito Bancário: uma Análise com Dados em Painel para as Maiores Instituições*
}

\section{Banking Credit in Brazil: a Panel Data Analysis of Larger Institutions}

José Ricardo Fucidji ${ }^{1}$

Diogo de Prince ${ }^{2}$

Resumo: Este trabalho apresenta novas evidências empíricas sobre o comportamento do crédito bancário, usando dados das treze maiores instituições bancárias locais. Após uma breve revisão da literatura sobre as mudanças no setor bancário após o Plano Real e a oferta de crédito, estimamos dados em painel para a amostra de bancos no período de março de 2001 a junho de 2006. Nossos principais resultados são (1) uma correlação inversa robusta entre operações de crédito e aplicações em títulos públicos; (2) correlação positiva e robusta entre grau de alavancagem e PIB a preços constantes, de um lado; e operações de crédito, de outro. As variáveis grau de alavancagem e aplicações em títulos públicos parecem confirmar a elevada preferência pela liquidez do setor bancário. A taxa Selic e o índice da Basiléia, também incluídos, não eram estatisticamente significativos.

Palavras-chave: Setor bancário. Crédito. Estratégias bancárias.

Abstract: This paper brings some new evidence on the banking behavior concerning credit, using bank-level data of the thirteen largest banks located in Brazil (domestic and foreign). After a brief overview of the literature on the Brazilian banking sector restructuring (following the Real Plan) and lending behavior, we implement a panel data analysis on our sample, from March 2001 to June 2006. The main results are: (1) a robust negative correlation between public bonds purchase and lending; and (2) a robust positive correlation between demand deposits, leverage and GDP at constant prices, on the one hand; and lending, on the other hand. These findings, particularly leverage and public bonds purchase, seem to confirm high liquidity-preference of the banking sector. Brazilian prime rate (Selic) and Basle index, also included, were of no-significance.

Keywords: Banking sector. Lending. Banking strategy.

JEL Classification: G20; G21; G28.

\footnotetext{
* Os autores agradecem o apoio financeiro da Fapesp à pesquisa da qual, em parte, resultou este trabalho.

1 Professor do Departamento de Economia da UNESP/FCL - Araraquara. Pesquisador do Grupo de Estudos de Economia Industrial (GEEIN) da UNESP/FCL. E-mail: jrfucidji@fclar.unesp.br

2 Mestrando em Economia da FEA-RP/USP. Pesquisador do Grupo de Estudos de Economia Industrial (GEEIN) da UNESP/FCL. E-mail: dioted@yahoo.com.br
} 


\section{Os Efeitos Esperados da Abertura do Setor Bancário}

Há uma extensa literatura sobre a entrada de bancos estrangeiros na economia brasileira a partir da segunda metade da década de 1990. Como já apontado em outros trabalhos, entre as motivações para a abertura do setor bancário brasileiro à atuação estrangeira a partir de 1995 estava a crença de que tais bancos poderiam: (a) ampliar e estabilizar os fluxos de capital externo para a economia brasileira, devido à maior integração dessa com o mercado financeiro internacional; (b) melhorar os níveis de eficiência operacional do setor bancário brasileiro, uma vez que os bancos entrantes seriam mais eficientes em seus países de origem; e (c) "aprofundar" o sistema financeiro, isso é, ampliar a oferta de crédito e de serviços financeiros para a economia de destino, diluir riscos e monitorar projetos e investidores, com efeitos positivos para o crescimento de longo prazo. O presente trabalho preocupa-se com esse último aspecto. ${ }^{3}$

Quanto ao primeiro aspecto, além das evidências empíricas serem inconclusivas, algumas delas apontam até uma correlação positiva entre abertura financeira e ocorrência de crises financeiras (ARESTIS, 2003). Quanto ao segundo aspecto, é inegável a eficiência em relação ao lucro dos bancos domésticos. ${ }^{4}$ Entre os efeitos esperados da abertura, Carvalho (2002) inclui efeitos positivos de bem-estar pela diversificação dos serviços oferecidos e a introdução de práticas superiores na área de banco de investimento e na análise de crédito pelos agentes estrangeiros. De acordo com o mesmo autor, esperava-se que a estrutura do mercado bancário após a abertura reproduzisse o padrão dos países desenvolvidos, com alguns poucos grandes bancos universais oferecendo produtos de varejo para mercados de massa e bancos de investimento fornecendo produtos sofisticados para clientes de alta renda e grandes empresas.

Porém, antes mesmo dos processos recentes de internacionalização do setor, os bancos estrangeiros atuantes no país já se concentravam nos mercados de alta renda e corporativos. Sua forma de atuação era, portanto, complementar à dos bancos nacionais, que dominavam o mercado (CARVALHO, 2000). Esperava-se assim que a entrada de bancos estrangeiros promovesse um "choque de competição" no mercado bancário,

3 Para uma análise do primeiro aspecto, ver Vasconcelos e Fucidji (2003); para o segundo aspecto, ver Carvalho (2003); quanto ao terceiro aspecto, ver Levine (2004), que condensa os argumentos da literatura sobre a relação entre finanças e desenvolvimento; e, para as críticas, ver Arestis (2003) e Carvalho (2002). A principal contribuição de nosso texto é apresentar evidências recentes sobre o comportamento do crédito bancário.

4 Um banco é eficiente em relação ao lucro se oferece a cesta de serviços que gera o máximo lucro, mesmo que para isso incorra em custos mais elevados - o acréscimo de lucros mais do que compensa o acréscimo de custos. A eficiência em relação ao custo ocorre quando um banco logra minimizar o custo de sua cesta de serviços. Ver Berger e Mester (1997; 1999). 
com ampliação do leque de produtos oferecidos e pressão sobre spreads e margens de lucro (YILDIRIM; PHILIPPATOS, 2007, p. 630).

Quanto ao terceiro aspecto, apresentamos, na seção 2, um breve retrospecto do comportamento dos bancos domésticos (nacionais e estrangeiros) após 1994. Na seção 3, serão apresentadas algumas evidências empíricas do comportamento dos maiores bancos locais em relação à oferta de crédito. Seguem-se as principais conclusões.

\section{Entrada de Bancos Estrangeiros e Crédito: 1994-2000}

A primeira grande mudança comportamental do setor bancário ocorreu com a implantação do Plano Real e a redução dos ganhos das instituições financeiras com o floating. Segundo pesquisa do IBGE, essas rendas representaram mais de $40 \%$ do valor adicionado do setor financeiro em 1991 e 1992 (CARVALHO, 2000). Os bancos locais passaram, então, a adotar uma postura mais agressiva em suas aplicações, o que é mostrado pela elevação do grau de alavancagem (G.A.) ${ }^{5}$ e pela porcentagem de operações de crédito no ativo dos bancos (DE PAULA et al., 2001), a qual perdura apenas até 1995, no caso do G.A., e até 1996, no caso da relação crédito/ativo. A Tabela 1 abaixo apresenta o grau de alavancagem e a participação do crédito no ativo para o período 1994-1998.

Tabela 1 - Grau de Alavancagem e Crédito/Ativo (em \%) 1994-1998

\begin{tabular}{c|c|c|c|c|c|c}
\hline & Jun/94 & Dez/94 & Dez/95 & Dez/96 & Dez/97 & Dez/98 \\
\hline G.A. & $\ldots$ & 6,08 & 10,13 & 5,75 & 5,87 & 5,18 \\
\hline Crédito/Ativo & 41,5 & 46,6 & 44,1 & 45,1 & 41,2 & 35,8 \\
\hline
\end{tabular}

Fonte: De Paula et al. (2001).

A expansão do crédito no período seguinte à implantação do Plano ocorreu a despeito de medidas governamentais para contê-la. A "demanda reprimida" por duas décadas de inflação elevada foi sendo atendida por empréstimos a prazos curtos, decorrentes da tentativa, por parte dos bancos, de evitarem o desencaixe entre operações ativas e passivas. Além disso, a confiança na expectativa da estabilização dos preços impulsionou os consumidores a ampliarem a demanda por bens duráveis por causa do aumento real do poder de compra dos salários (CERQUEIRA, 1998; CINTRA, 2006).

5 O grau de alavancagem é medido pela razão ativo total menos encaixe bancário menos títulos do governo sobre o patrimônio líquido. Esse indicador mede o grau de agressividade do banco nas suas aplicações (ativo). Isso porque em caso de aplicações mal-sucedidas (principalmente empréstimos), maior será o comprometimento do patrimônio líquido - e o risco de insolvência. 
Porém, essa expansão do crédito bancário teve curta duração. Com a redução dos influxos de capitais por causa da crise mexicana de 1994, o Banco Central aumentou a taxa de juros. Esse choque de juros causou aumento da inadimplência no segundo semestre de 1994. Isso fragilizou o sistema bancário e trouxe a possibilidade de crise sistêmica. O sistema bancário ainda sofreria o impacto de um aumento dos depósitos compulsórios, ${ }^{6}$ o que restringiu a liquidez do setor (CINTRA, 2006). O Banco Central freou a expansão do crédito ao impor também um "compulsório de $15 \%$ sobre os créditos concedidos, diante da relativa ineficácia dos elevados compulsórios sobre depósitos à vista e a prazo" (DE PAULA et al., 2001, p. 304).

A reação às medidas de contração da liquidez do governo para os grandes bancos foi manter juros e spreads elevados para compensar os maus resultados da carteira de crédito. Assim, os bancos conseguiram manter suas margens de lucro em 1995 e 1996 direcionando seus ativos para operações com títulos públicos. Os bancos passaram a adotar um comportamento de maior preferência pela liquidez e aversão ao risco mostrado pela tendência de queda do grau de alavancagem dos bancos múltiplos privados a partir de 1995, como mostrado na tabela acima. Com a contração da liquidez e o aumento da inadimplência, reforçados por essas políticas restritivas (CHICK; DOW, 2002), os bancos passaram a ser mais seletivos na oferta de crédito, e diminuíram os empréstimos no interbancário para as instituições financeiras mais dependentes dessa fonte de recursos (CINTRA, 2006).

Essa reversão de comportamento foi interpretada por José Maria Fanelli e Roberto Frenkel como a persistência do comportamento bancário típico de alta inflação num contexto de baixa inflação. Embora os dados acima apoiem essa interpretação (e também De Paula et al., 2001, p. 302), acreditamos que seja necessário fazer uma qualificação. Com a queda da inflação, os bancos efetivamente modificaram seu comportamento; o que ocorreu a seguir foi uma readaptação do setor a uma mudança repentina e adversa do ambiente econômico, fortemente delineado pela política monetária. Nesse exato sentido, seguindo as observações de Carvalho (2005), podemos dizer que foram os fatores indutores de comportamento dos bancos - quais sejam, a política monetária e as causas dela - os responsáveis pela reação à crise bancária de 1994-95 e não uma suposta inércia comportamental em relação ao período de alta inflação. ${ }^{7}$

$6 \quad$ As alíquotas de recolhimento compulsório eram de 83\% sobre depósitos à vista, 30\% sobre depósitos a prazo e 30\% sobre depósito de poupança em abril de 1995. Ver seção "Moeda e Crédito" do Relatório Anual do Banco Central de 2005. Essas alíquotas dão a dimensão da restrição de liquidez sobre o sistema bancário.

7 Esse episódio inclusive ilustra a capacidade de rápida adaptação do setor aos incentivos sistêmicos. 
Para fortalecer e reestruturar o setor, frente a uma crise bancária já em andamento, o governo criou o Programa de Incentivo à Redução do Setor Público Estadual na Atividade Bancária (PROES) e o Programa de Estímulo à Reestruturação e ao Fortalecimento do Sistema Financeiro (PROER). Assim, por um lado, com o PROES, os bancos estaduais passaram ao controle federal para serem privatizados posteriormente. ${ }^{8}$ Por outro lado, o PROER favorecia a mudança de controle dos bancos privados. Portanto, esses dois mecanismos foram uma via de entrada dos bancos estrangeiros no mercado brasileiro, pelo incentivo à transferência de controle. Além disso, a crise bancária de 1995 desvalorizou as instituições financeiras do país. Dos bancos sob administração do Banco Central - tanto públicos como privados (sendo o Nacional e o Econômico os casos mais notórios) - os créditos inadimplentes foram absorvidos pelo Banco Central, enquanto os bancos estrangeiros ficaram com os "bons" ativos. Ademais, um processo de consolidação bancária envolvendo apenas bancos nacionais seria inviável, pois resultaria em um sistema bancário altamente concentrado (CARVALHO, 2002, p. 13).

Além desses fatores "atratores" do capital estrangeiro no setor, em nível internacional havia também fatores "indutores". Com a consolidação bancária internacional, os grandes bancos expandiram sua atuação aos mercados emergentes, a fim de utilizar suas vantagens presumidas, aumentando lucros e escalas, já que enfrentavam uma pressão competitiva nos mercados maduros. Contudo, entre os aspectos desfavoráveis para os bancos entrantes estava, além da falta de conhecimento local (idioma e cultura), a grande participação de mercado dos bancos domésticos (CARVALHO, 2002, p. 13).

Quanto à oferta de crédito no Brasil, pode-se afirmar que os bancos estrangeiros adotaram uma posição conservadora no país, a partir de 1994. As instituições financeiras estrangeiras obtiveram maior rentabilidade do que as nacionais, mas por direcionar seus recursos para títulos públicos, enquanto a razão operações de crédito/ativo total era maior nos nacionais privados, contrariando o que muitos prediziam. Vale dizer, os ganhos com operações de tesouraria eram muito atrativos para permitir a expansão do crédito desses bancos.

Não obstante, as instituições estrangeiras aumentaram sua participação na captação externa do setor bancário (CINTRA, 2006). Os bancos estrangeiros foram responsáveis por $31 \%$ da captação de recursos externos em 1995, alcançando 55,5\% em 2000. ${ }^{9}$ Apesar de os bancos nacionais

8 O custo do PROES foi estimado em US\$ 50,6 bilhões pelo Banco Central (CINTRA, 2006).

9 Para a participação dos bancos estrangeiros na captação externa da área bancária, ver Cintra (2006). 
terem perdido participação nas captações externas, de 69,1\% em 1995 para 45,5\% em 2000, posteriormente ocorreu uma recuperação, com o que essa participação atingiu 53,9\% em 2003 (CINTRA, 2006). Na década de 1990, tomar recursos no exterior a taxas de juros menores que as do mercado local e fazer empréstimos com esses recursos a taxas mais elevadas foi uma forma de os bancos obterem lucros significativos (DE PAULA et. al., 2001). Segundo os mesmos autores, o ativo externo cresceu menos do que o passivo externo nos balanços das instituições financeiras até 1997, levando a um aumento da exposição ao risco cambial dos bancos.

Como efeitos gerais, pode-se dizer que, apesar da entrada das instituições estrangeiras, a estrutura do mercado bancário permaneceu significativamente concentrada no fim da década de 1990 (YILDIRIM; PHILIPPATOS, 2007). A margem de intermediação financeira manteve-se elevada, com base na evidência dos spreads bancários (DE PAULA; MARQUES, 2006). Isso mostra que também não houve significativa dispersão de comportamento entre as instituições nacionais e estrangeiras. A despeito das elevadas margens de intermediação, Faria et al. (2007) destacam, como resultado, o aumento da eficiência de intermediação dos seis bancos que mais participaram do processo de fusões e aquisições bancárias. A taxa de juros elevada e as operações de tesouraria proporcionam altos rendimentos, o que explica a participação relativamente baixa das receitas com tarifas em relação às receitas bancárias totais no país, num primeiro momento, apesar do crescimento dessa participação, recentemente. ${ }^{10}$ Uma outra especificidade brasileira é o aumento da lucratividade dos bancos privados nacionais após a entrada das instituições estrangeiras (GUIMARÃES, 2002 apud FARIA et al., 2007), contrariando a literatura internacional.

É importante, neste ponto, diferenciar duas estratégias de inserção no mercado bancário: (I) as operações de varejo, que focalizam a atuação no crédito ao consumo (incluindo, desde 2004, também as operações de crédito consignado); e (II) as operações de bancos de investimento, que atuam na área de finanças corporativas e administração de recursos. A busca de clientes de alta renda por parte dos principais bancos locais é um aspecto dessa segunda estratégia, caracterizando o que Dymski (2004) denomina "exclusão financeira". A captação de depósitos perdeu importância nas estratégias bancárias, por envolver custos operacionais de mão-de-obra e agências. Esses custos foram explicitamente compensados pela cobrança de tarifas; ainda assim o depósito à vista é um instrumento de baixa lucratividade para a venda cruzada de serviços financeiros (CARVALHO, 2000, p. 23).

Portanto, um dos aspectos mais proeminentes das mudanças recentes no setor bancário foi a reação dos bancos nacionais à penetração estrangeira. Os bancos nacionais recuperaram a hegemonia nas operações de

10 Ver "Tarifas Bancárias Crescentes" (O Estado de São Paulo, 11 de novembro de 2006). 
varejo mediante aquisições de bancos nacionais e estrangeiros, e não perderam sua liderança na área de bancos de investimento. Os bancos privados nacionais apresentaram ganhos de eficiência operacional maiores que os estrangeiros, de acordo com os estudos de Alves Jr. et al. (2002) e Marques e De Paula (2004). Além disso, Faria et al. (2007) registram economias de escala para os bancos privados nacionais entre 1995 e 1999 e apontam a presença de economias de escala e de escopo após as fusões e aquisições bancárias. A estratégia de reação dos bancos nacionais privados à entrada dos bancos estrangeiros incluiu ainda o aumento da internacionalização (investimentos no exterior) dos três maiores bancos privados nacionais (CINTRA, 2006).

Quanto ao comportamento agregado do crédito, o período concomitante ou posterior às modificações estruturais no setor bancário, isso é, a segunda metade dos anos 90, não demonstrou nenhum avanço em relação ao padrão de oferta de crédito no país, como se pode ver pelo Gráfico 1, abaixo. Por ele, confirma-se a assertiva frequente de que a oferta de crédito no país é extremamente modesta, mesmo para os padrões de outros países em desenvolvimento, com um sistema bancário de estrutura semelhante. Após a expansão dos doze meses entre abril de 1994 e março de 1995, em que atingiu seu maior valor (36,4\%), a oferta de crédito voltou a declinar, oscilando sempre abaixo dos $30 \%$ do PIB e atingindo um mínimo de $21,8 \%$ no primeiro trimestre de 2003 . Desde então o crédito vem se expandindo (de forma mais consistente a partir do terceiro trimestre de 2004), para atingir 31,1\% no primeiro trimestre de 2007.



Gráfico 1 - Razão (\%) Crédito/PIB - $1^{\circ}$ trimestre de 1994 a $1^{\circ}$ trimestre de 2007 Fonte: Elaboração própria, a partir dos dados do Bacen. Médias trimestrais. 
As explicações tradicionais para a baixa agressividade dos bancos ingressantes na oferta de crédito dizem respeito à origem do capital. Dages, Goldberg e Kinney (2000) apontam que os bancos ingressantes na Argentina e no México, predominantemente europeus, conviviam com um ambiente competitivo e regulatório frouxo em seus países de origem, o que permitia a coexistência de instituições eficientes e ineficientes. Esse ambiente de mercado contrastaria com o norte-americano, onde as modificações regulatórias, ao ampliarem a contestabilidade das posições estabelecidas, eliminaram as instituições menos eficientes (em custos) e menos empreendedoras (na oferta de crédito) (CARVALHO, 2002).

Levando em conta as diferentes estratégias por origem de capital, vale lembrar que os bancos europeus ingressaram no mercado doméstico via aquisições, enquanto os norte-americanos permaneceram em suas áreas de atuação tradicionais. Dessa forma, a situação financeira e a inserção de mercado das instituições adquiridas, segundo os mesmos autores, seria mais importante para explicar a atuação dos bancos ingressantes do que a origem de seus controladores (CARVALHO, 2002, p. 10).

No caso brasileiro, as explicações para o baixo crédito costumam apontar aspectos da estrutura de mercado e das estratégias das firmas bancárias. ${ }^{11}$ Quanto à estrutura, parece não haver dúvida de que a entrada de bancos estrangeiros promoveu um aumento da concentração do setor (com efeitos negativos sobre o atendimento bancário e o crédito). Nakane (2001, p. 19), usando dados mensais dos 17 maiores bancos locais entre agosto/1994 e agosto/2000, estima a elasticidade da oferta de crédito $(\lambda)$ do mercado bancário ao aumento da oferta de crédito por um banco. O parâmetro $\lambda$, segundo o autor, é um indicador do poder de mercado do setor bancário: $\lambda$ unitário indica comportamento monopolista; $\lambda$ nulo, concorrência perfeita; e $0<\lambda<1$ os "casos intermediários". Sua conclusão é que, embora o mercado bancário seja altamente concentrado, não pode ser considerado não-competitivo (o valor estimado de $\lambda$ é 0,0017 , estatisticamente significativo a 5\%) (NAKANE, 2001, p. 19).

Vasconcelos et al. (2004), usando dados mensais do crédito bancário total entre os estados brasileiros entre agosto/1994 e novembro/2002, apresentam diversas medidas de concentração do crédito e um modelo de dados em painel para os determinantes do crédito. Concluem que não apenas houve aumento de concentração associado às aquisições no setor, mas também que a concentração da oferta de crédito - e do atendimento

11 Essa classificação binária envolve, é claro, um juízo de valor a respeito das explicações dadas pelos representantes do setor. Embora a insegurança jurídica e a chamada "cunha fiscal" certamente elevem o "preço" do crédito bancário, acreditamos que o comportamento dos bancos seria mais agressivo, fosse outro, ceteris paribus, o ambiente competitivo (ver, por exemplo, a opinião de Fábio Barbosa, vice-presidente do ABN Amro, em Conjuntura Econômica, vol. 59, no. 6, junho de 2005, p. 49). 
bancário em geral - foi favorável às Regiões Sudeste e Sul. O mesmo é apontado por Yildirim e Philippatos (2007, p. 634) que, apresentando dados para o conjunto dos países da América Latina, utilizam medidas mais simples, como o índice de concentração de Herfindhal-Hirschman.

Quanto ao comportamento dos bancos, pode-se concluir, a partir da exposição sumária até aqui que, enquanto a eficiência-lucro microeconômica continuou positiva, em termos de funcionalidade macroeconômica (expansão da oferta de crédito), as mudanças estruturais no setor se mostraram frustrantes. Os bancos ingressantes não "contestaram" as posições - e principalmente a conduta de mercado - das instituições locais, deixando intocada inclusive a posição de liderança dos bancos privados nacionais. Muito pelo contrário: sua estratégia não só seguiu como aprofundou o padrão setorial de atuação nos mercados de títulos e valores mobiliários, expandindo apenas gradualmente do crédito ao consumo, além dos repasses de recursos de agências oficiais de financiamento. A principal mudança do último lustro quanto a essa conclusão é a expansão recente dos empréstimos consignados, ou seja, fortemente garantidos, o que reforça uma vez mais o caráter conservador de suas estratégias. ${ }^{12}$

A seguir, procuramos testar a significância da relação entre o volume do crédito bancário das 13 maiores instituições no país e uma série de variáveis, procurando captar efeitos - tanto da política econômica quando do comportamento dos bancos - que possam explicar a oferta de crédito no país. Deve-se notar que tal exercício é de caráter exploratório e seria mais correto afirmar que estamos em busca da mensuração robusta dos determinantes do crédito.

\section{Análise Empírica do Comportamento do Crédito Bancário - 2001-2006}

\subsection{Amostra e especificação do modelo}

Para a análise do comportamento do crédito bancário, selecionamos inicialmente as quinze maiores instituições bancárias por ativo total em dezembro de 2005. Dessa lista foram excluídas as duas últimas instituições: (I) o Banco Pactual, um banco de atacado cujo ativo total representava a metade do ativo do décimo banco; e (II) o Banrisul, um banco público estadual muito regionalizado. ${ }^{13}$ Assim, a amostra é composta por 13 bancos,

12 Um estudo mais detalhado das estratégias bancárias e da disputa pelos empréstimos com desconto em folha de pagamento e a partir dos benefícios do INSS está além do escopo do presente texto, mas faz parte da pesquisa em que ele está inserido.

13 Pelo mesmo critério deveríamos excluir a Nossa Caixa. Contudo, interessa-nos averiguar se o acordo recente para que esse banco seja o depositário dos rendimentos dos funcionários 
sendo nove de varejo e quatro de atacado (Safra, Citibank, Votorantim e BankBoston). Após a definição da amostra, o Itaú adquiriu o BankBoston, ${ }^{14}$ mas, como o exercício econométrico cobre o período março/2001 a junho/2006, ele ainda aparece como uma das unidades de análise. Os dados apresentados na Tabela 2 apontam a elevada concentração do sistema bancário brasileiro: por qualquer dos critérios, os bancos da amostra representam mais de $80 \%$ do total do sistema bancário consolidado em março de 2007.

Todos os dados utilizados foram obtidos na página do Banco Central do Brasil na Internet. Nosso objetivo é encontrar variáveis significativamente correlacionadas com a oferta de crédito dos bancos da amostra. Como não existe, até onde sabemos, nenhum modelo explicativo para o crédito que forneça formas funcionais prontamente testáveis, utilizamos uma série de estudos para definir as candidatas a variáveis explicativas no modelo de dados em painel.

A variável dependente é o volume de operações de crédito $(\mathrm{V})$, que é estoque das carteiras de cada banco, incluindo todas as modalidades, em milhares de reais deflacionados pelo IPCA de janeiro de 2001.

As variáveis independentes procuram captar aspectos da estratégia dos bancos (depósitos à vista, grau de alavancagem), da política econômica (índice da Basileia, razão títulos/ativo e taxa Selic, embora os dois primeiros, assim como o grau de alavancagem, representem também a preferência pela liquidez dos bancos) e da demanda por crédito (PIB). Incluímos também uma variável para captar a qualidade dos empréstimos: a razão provisões para inadimplência/crédito.

O montante de depósitos à vista (DV) foi incluído por representar uma fonte de captação para o banco. Apesar dos bancos serem capazes de criar crédito independentemente da existência prévia de depósitos na visão pós-keynesiana (WRAY, 2003), a variável depósitos à vista foi introduzida no modelo para captar a importância dessa fonte de recursos para expansão do crédito. O volume de depósitos à vista (em milhares de reais) foi deflacionado pelo IPCA com mês-base em janeiro de 2001.

O grau de alavancagem (GA) indica a preferência pela liquidez dos bancos, de acordo com De Paula et al. (2001). Um aumento do grau de alavancagem indica uma postura mais agressiva do banco na composição do ativo, já que implica também a disposição do banco em assumir maior risco de insolvência, como já exposto. Essa variável foi construída pela fórmula (ativo total - encaixes - títulos/patrimônio líquido). Grosso modo, representa o inverso da proporção entre patrimônio líquido e empréstimos.

públicos paulistas altera, de alguma forma, sua atuação.

14 Nessa aquisição, o Itaú emitiu $R \$ 4,5$ bilhões de reais em ações e, com isso, o Bank of America passou a controlar 5,8\% do capital total do Itaú (Valor, 03 de maio de 2006). 


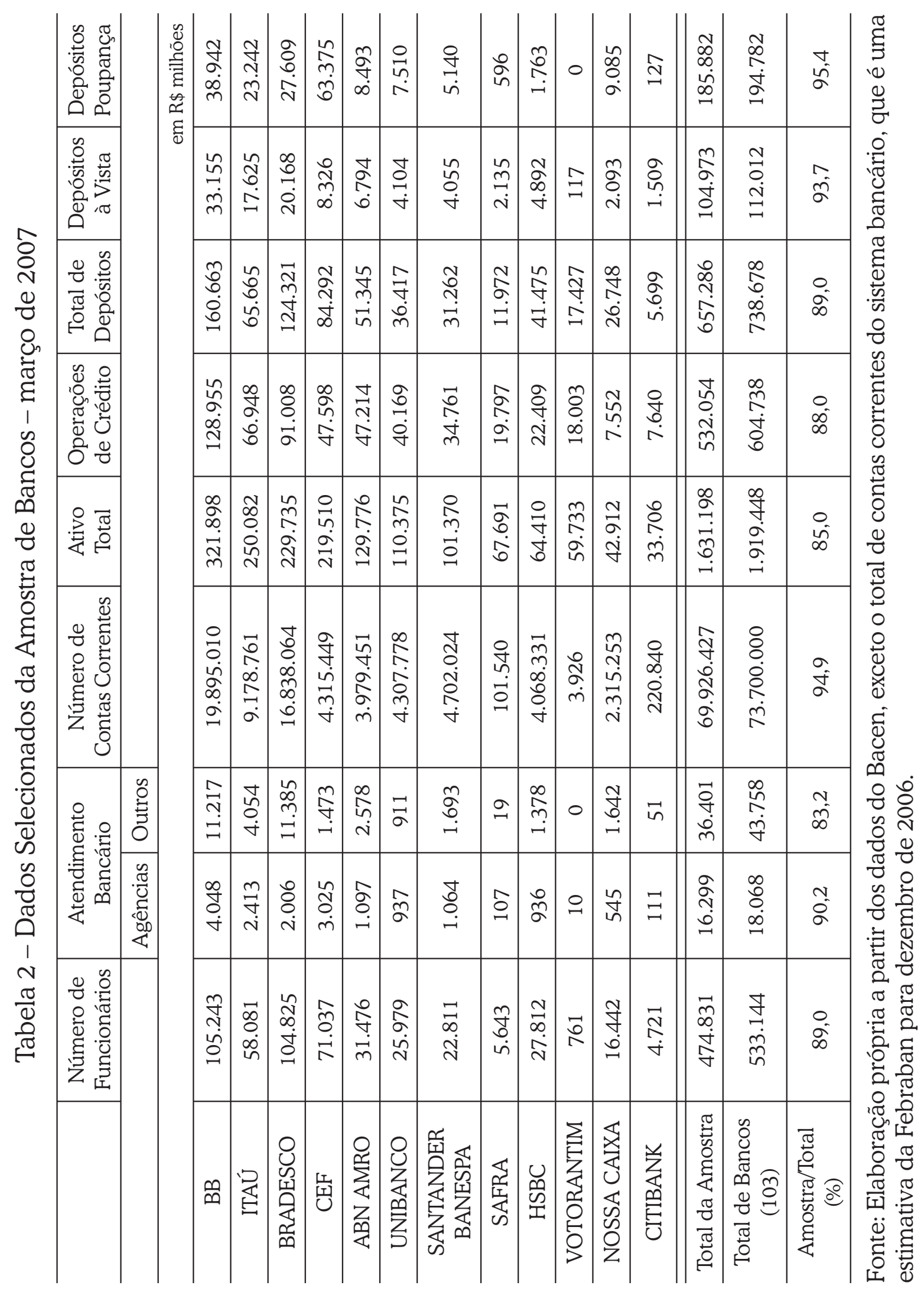


O índice da Basileia (IB) é a razão capital próprio/ativo total, em que o denominador é ponderado por graus de risco diferenciados para os itens que o compõem. O índice mínimo exigido pelo Banco Central é de $11 \%$ (ou seja, para cada $R \$ 100$ de ativos ponderados pelo risco, o banco deve ter $R \$ 11$ de capital próprio). Essa norma prudencial eventualmente limitaria a capacidade dos bancos de concederem empréstimos, já que esses são ponderados pelo fator de risco máximo, enquanto o fator de risco dos títulos públicos é nulo. De fato, Soares (2001) já apontou que a introdução dessa norma, ao incentivar a composição do ativo com títulos públicos, seria um fator restritivo à expansão do crédito. As autoridades monetárias brasileiras seriam ainda mais "prudentes" que as internacionais, visto que o país aplica um índice 3 pontos acima do exigido pelo Acordo da Basileia. Contudo, os bancos locais são ainda mais tímidos que as autoridades monetárias: os bancos da amostra mantêm um IB médio (ponderado pelo tamanho) de 17,35\%. Por isso, essa variável, assim como o grau de alavancagem, indica não o efeito da norma prudencial, mas a preferência pela liquidez dos bancos. Contudo, Blum e Nakane (2005) argumentaram que quanto maior o índice da Basileia no tempo $t$, maior a capacidade do banco elevar os empréstimos em $t+1$, pois possui mais capital próprio em relação ao de terceiros. Assim, essa variável foi selecionada pelo seu interesse para o debate. Com ela, incluímos também a variável títulos (T) que é razão títulos públicos/ativo total.

A taxa Selic (SELIC) média trimestral foi incluída com base nos mesmos argumentos acima. Mas enquanto a variável T capta o efeito quantidade de títulos, a variável SELIC capta o efeito preço dessas aplicações.

Finalmente, a variável que procura captar o efeito da demanda por crédito é o PIB (em milhões de reais) deflacionado pelo IPCA com mêsbase em janeiro de 2001, também utilizada em Blum e Nakane (2005). Inicialmente, incluímos também uma variável para captar a qualidade dos empréstimos. Informações da imprensa de negócios apontam que os bancos "freiam" a concessão de crédito quando percebem elevação da inadimplência e, portanto, são obrigados a aumentar as provisões para default nessas operações. ${ }^{15}$ A variável qualidade dos empréstimos (Q) - razão provisão/operações de crédito -, cujo sinal esperado é negativo, procurava captar esse efeito. Embora essa variável tenha se mostrado significativa e com o sinal esperado, optamos por excluí-la do modelo até obtermos mais informações sobre os limites mínimos legais dessas provisões, para depois descontarmos a "provisão legal".

O modelo de dados em painel resultante a ser testado é o seguinte:

15 Ver a respeito as reportagens "Lucros crescem, apesar da inadimplência" (Valor Econômico, 12 de maio de 2006) e "Unibanco desacelera crédito" (Valor Econômico, 11 de agosto de 2006). 


$$
V_{i t}=a+\beta_{1} D V_{i t}+\beta_{2} G A_{i t}+\beta_{3} I B_{i t}+\beta_{4} T_{i t}+\beta_{5} S E L I C_{i t}+\beta_{6} P I B_{i t}+f_{i}+\varepsilon_{i t}
$$

Onde,

$f_{i}=$ é o efeito específico a cada banco e invariante no tempo;

$\varepsilon_{i t}=$ é o termo de erro aleatório.

Como já apontado, o presente exercício cobre 22 trimestres (março/ 2001 a junho/2006) e os 13 maiores bancos, perfazendo 286 observações. ${ }^{16}$ Ao definir o modelo, discutiu-se a possível presença de endogeneidade das variáveis DV, IB, e T com V, por serem decididas simultaneamente pelo banco. Para testá-la, rodamos os três modelos auxiliares que refutaram a presença de endogeneidade dos regressores citados, apresentados na tabela A1 do anexo. ${ }^{17}$ Todos os modelos a seguir foram estimados pelo método dos Mínimos Quadrados Ordinários (MQO).

\subsection{Estimação e Resultados}

O primeiro modelo a ser estimado (modelo (4) na Tabela 3) indicou a presença de efeitos fixos. Os efeitos fixos são variáveis omitidas que variam entre os indivíduos, mas não ao longo do tempo (HSIAO, 2003, p. 30). Como os efeitos fixos são constantes no decorrer do tempo, a influência desses efeitos é eliminada ao se fazer uma comparação entre períodos (modelo em diferenças), no qual apenas os fatores que variam entre períodos para explicar a variável dependente são considerados.

Ao se tomar as diferenças das variáveis da equação (1) temos:

$$
V_{i t}=a+\beta_{1} \Delta D V_{i t}+\beta_{2} \Delta G A_{i t}+\beta_{3} \Delta I B_{i t}+\beta_{4} \Delta T_{i t}+\beta_{5} \Delta S E L I C_{i t}+\beta_{6} \Delta P I B_{i t}+\varepsilon_{i t}
$$

Assim, busca-se estimar a tendência da variável dependente, não se fazendo inferências sobre o seu nível absoluto (no qual os efeitos fixos teriam influência). A perda de 13 graus de liberdade foi o custo para realizar o modelo em diferenças, mas que não é elevado face às 273 observações remanescentes nas regressões em diferenças (modelos (1) e (2).

A regressão é significativa, com poder explicativo relevante. A proporção de títulos no ativo figura no modelo (1) como não-significativa. $\mathrm{Na}$ verdade, tanto a variável SELIC como T captam o mesmo efeito, a aplicação do ativo bancário em títulos públicos, ao invés de empréstimos. Por isso, retira-se uma das duas variáveis para verificar se a presença multicolinearidade causa inconvenientes à estimação. Duas regressões auxiliares

16 Na metodologia de dados em painel é comum utilizar o número de unidades entre 10 e 100, observando-as no tempo (BECK; KATZ, 1995, p. 634).

17 O teste de endogeneidade é composto de duas etapas: (I) roda-se a regressão com a variável acusada de endogeneidade como dependente dos demais regressores; (II) o resíduo da regressão da primeira etapa é utilizado como variável explicativa do modelo com V como dependente. Se os resíduos da etapa (II) não forem significativos, a endogeneidade da variável é descartada. 
(não apresentadas) foram estimadas, uma com T outra com SELIC como variáveis dependentes. A regra prática de Klein estabelece que, se o $\mathrm{R}^{2}$ das regressões auxiliares for maior que o da regressão principal, a presença de multicolinearidade causa inconvenientes à estimação (GUJARATI, 2000 , p. 336). Não foi esse o caso, uma vez que o $R^{2}$ da regressão com $T$ como variável dependente é 0,0564 e o da regressão em que SELIC figura como variável dependente é 0,2564 . Ambos são, portanto, menores que o $R^{2}$ do modelo (1), que é 0,5726. Quando eliminamos as variáveis não significativas (IB e DV - que aparece com sinal contrário ao esperado) no modelo (2), a variável T torna-se significativa a 10\%, porém com sinal contrário ao esperado. ${ }^{18}$ As demais variáveis, no entanto, apresentam o sinal esperado e são significativas: o modelo indica que os aumentos do grau de alavancagem e do PIB tendem a elevar a média da oferta de crédito bancário. Como ilustração, para cada ponto percentual de redução da taxa Selic, haveria um aumento médio de crédito na ordem de $\mathrm{R} \$ 82,7$ milhões constantes.

Tabela 3 - Resultados das Regressões

\begin{tabular}{c|c|c|c|c|c|c}
\hline \multirow{2}{*}{\multicolumn{2}{c|}{}} & \multicolumn{2}{|c|}{ Modelos em Diferenças } & \multicolumn{3}{c}{ Modelos em Nível } \\
\cline { 3 - 7 } \multicolumn{2}{l|}{} & $(1)$ & $(2)$ & $(3)$ & $(4)$ & $(5)$ \\
\hline Constante & $397.950,5 * * *$ & $401.829,9 * * *$ & $-1,59$ & $-14,43 * * *$ & $-12,38 * * *$ \\
\hline DV & $(+)$ & $-0,05$ & & $0,13 * * *$ & $-0,01$ & \\
\hline GA & $(+)$ & $893.502,9 * * *$ & $919.804,4 * * *$ & $0,82 * * *$ & $0,58 * * *$ & $0,61 * * *$ \\
\hline IB & $(-)$ & $-39.760,6$ & & $-0,13$ & $-0,04$ & \\
\hline T & $(-)$ & $28.599,1$ & $33.022,7 *$ & $-0,11 * * *$ & $-0,03 * * *$ & $-0,29 * * *$ \\
\hline SELIC & $(-)$ & $-86.167,6 * *$ & $-82.736,4 * *$ & 0,07 & 0,07 & \\
\hline PIB & $(+)$ & $32,8 * *$ & $34,8 * * *$ & 1,19 & $2,41 * * *$ & $2,24 * * *$ \\
\hline \hline$N$ & & 273 & 273 & 286 & 286 & 286 \\
\hline R & & 0,5820 & 0,5789 & 0,5831 & 0,9590 & 0,9586 \\
\hline$R^{2}$ Ajust & & 0,5726 & 0,5726 & 0,5741 & 0,9563 & 0,9563 \\
\hline F & & 61,74 & 92,09 & 65,03 & 347,28 & 416,71 \\
\hline Prob(F) & & 0,00 & 0,00 & 0,00 & 0,00 & 0,00 \\
\hline Os
\end{tabular}

Os sinais esperados das variáveis estão entre parênteses.

* indica significância a 10\%; ** indica significância a 5\%;

*** indica significância a $1 \%$.

Os modelos em nível estão com as variáveis em logaritmos.

18 Esse resultado possivelmente confirma a hipótese de Blum e Nakane (2005), segundo os quais o aumento do índice da Basileia (no qual os títulos recebem ponderação de risco nulo) incentiva os bancos a concederem crédito no período subsequente. No entanto, nos modelos em nível, T aparece com o sinal esperado e é altamente significativa. 
Contudo, essa é uma forma simplificada de lidar com os efeitos fixos. Uma maneira alternativa é retornar ao modelo em nível e estimar o modelo (3) e incluir os efeitos fixos (4). ${ }^{19}$ Devido ao ganho de poder explicativo do modelo (4) em relação ao (3), podemos dizer que os efeitos fixos são significativos. Portanto, devemos incluir os efeitos fixos, o que é feito nos modelos (4) e (5).

Com o modelo (4) fizemos as mesmas regressões auxiliares (não apresentadas) feitas para o modelo (1), com o intuito de verificar eventuais inconvenientes derivados de multicolinearidade. Novamente, podemos descartar esse tipo de problema, pois o $\mathrm{R}^{2}$ obtido quando colocamos $\mathrm{T}$ como variável dependente é 0,1053 e, quando colocamos SELIC como variável dependente, é 0,0523 - ambos menores que o $\mathrm{R}^{2}$ do modelo (3).

Chegamos por fim aos modelos em nível com efeitos fixos (a diferença entre os modelos (4) e (5) é que desse último foram retiradas as variáveis não-significativas). $\mathrm{O}$ modelo (5) é significativo pelo teste $\mathrm{F}$ e possui elevado poder explicativo $\left(\mathrm{R}^{2}\right)$. Ademais, os resultados em nível com efeitos fixos apresentam elevada significância para algumas das variáveis dos modelos anteriores (como GA, T e PIB). Note-se que, no modelo em nível, T torna-se mais significativo e apresenta o sinal esperado. Para um por cento de aumento dessas aplicações no ativo total, espera-se que o volume de crédito se reduza, para a média da amostra, cerca de $0,3 \%$. As variáveis PIB e GA continuam significativas, quando se passa do modelo (2) para o modelo (5). Elas mostram que para cada aumento de um por cento do PIB, o volume de crédito aumenta, em média, 2,24\%. Por outro lado, para cada acréscimo de um por cento no grau de alavancagem dos bancos, espera-se um aumento médio no crédito de 0,61\%. Em conjunção com dados mais qualitativos, esses dados confirmam o comportamento "tímido" dos maiores bancos em relação à oferta de crédito.

As novidades entre os modelos (2) e (5) são, primeiro, que a taxa Selic perde significância. Uma hipótese para explicar isso seria que para o comportamento do crédito importa não a taxa básica de juros, mas sim o spread bancário, que representa o aumento do "preço" do crédito para o tomador. O índice da Basileia não se mostrou significativo em nenhuma das regressões. Uma possível explicação seria que, uma vez que os bancos locais mantêm índices da Basileia em média superiores ao exigido pelo Acordo e mesmo pelo Banco Central, essa variável não é importante para explicar o comportamento do crédito.

19 A diferença é que, enquanto o modelo (3) desconsidera $f_{i}$ na equação (1), o modelo (4) estima a equação (1) completamente. 


\section{Considerações Finais}

Na literatura sobre a evolução recente do sistema financeiro nacional, particularmente o setor bancário, o principal aspecto destacado é a divergência entre os efeitos (positivos) esperados das mudanças no setor (implementadas num contexto de quase crise bancária) e os resultados (negativos) verificados posteriormente, em particular a persistência da disfuncionalidade do setor bancário ao desenvolvimento econômico, tanto no acesso da população a serviços bancários a preços competitivos, quanto na oferta de financiamento e monitoramento dos projetos empresariais. Desde a Reforma Bancária de 1965 os bancos locais nunca foram fonte relevante de funding para as empresas. Talvez seja desavisado aquele que deseja que eles o sejam.

Tanto a literatura sobre o comportamento das instituições bancárias a partir do Plano Real, quanto as evidências empíricas - aqui restritas ao período 2001-2006, a partir do qual se tornaram disponíveis as Informações Financeiras Trimestrais do Banco Central do Brasil - parecem confirmar que o ambiente competitivo no qual se inserem os bancos locais e os incentivos da política econômica conspiram para que uma elevada eficiência e lucratividade microeconômica conviva com estratégias em que persiste a elevada preferência pela liquidez das instituições. Daí o caráter desavisado da crítica: talvez os bancos sejam eficientes e lucrativos como o são exatamente porque não abrem mão das opções de aplicação de capital que oferecem a riqueza em sua forma mais geral, a liquidez.

Assim, nos estreitos limites em que um exercício econométrico se inscreve (no tempo e no espaço restrito da amostra e no contexto em que "explicação" não tem o sentido forte de causalidade) o presente texto parece confirmar um comportamento bancário altamente eficiente, mas disfuncional ao desenvolvimento. Muito mais trabalho é ainda necessário para refinar e ampliar as evidências; passamos a apontar algumas direções futuras para a pesquisa.

Em primeiro lugar, deve-se incorporar com maior intensidade as informações qualitativas vindas de estudos setoriais, relatórios dos bancos e da imprensa especializada. Elas permitem delinear um conjunto de estratégias em que se pode destacar eventuais diferenças de comportamento entre bancos. Em particular, a diferença por segmento de mercado - que foi aqui ignorada - pode ser um primeiro passo para identificar tais diferenças. Em segundo lugar, outras variáveis, como a composição do crédito, a qualidade do crédito e os spreads bancários devem ser incluídos na análise dos determinantes do crédito. Dessa forma, espera-se encontrar as motivações (indutores) e o destino (receptores) do crédito bancário. Finalmente, mais estudos sobre os determinantes institucionais do crédito bancário, no sentido apontado por Arestis (2003) e Carvalho (2005) são 
necessários. A relevância desse estudo não pode ser exagerada numa economia em que ao mesmo tempo o mercado de capitais é bank-based e a oferta de crédito é tão baixa.

\section{Referências}

ALVES JR, A. J.; CARVALHO, C. E.; STUDART, R. Desnacionalização do Setor Bancário e Financiamento das Empresas: a Experiência Brasileira Recente. Texto para Discussão IPEA, n. 882, maio 2002.

ARESTIS, P. Finance and Development: Institutional and Policy Alternatives to Financial Liberalization. Levy Economics Institute Working Paper, n. 377, April 2003.

BECK, N.; KATZ, J. What to Do (And Not to Do) With Time-Series Cross-Section Data. American Political Science Review, v. 89, n. 3, p. 634-647, Sep. 1995.

BERGER, A. N.; MESTER, L. J. Inside the Black Box: What Explains Differences in the Efficiencies of Financial Institutions?. Journal of Banking and Finance, v. 21, n. 7, p. 895947, July 1997.

BERGER, A. N.; MESTER, L. J. What Explains the Dramatic Changes in Cost and Profit Performance of the US Banking Industry?. Wharton Financial Institutions Centre Working Paper, n. 99-10, Feb. 1999.

BLUM, D. NAKANE, M. I. O impacto de requerimentos de capital na oferta de crédito bancário no Brasil. Anais do XXXIII Encontro Nacional de Economia, Natal, mimeo, 2005.

CARVALHO, F. J. C. New Competitive Strategies of Foreign Banks in Large Emerging Economies: The Case of Brazil. IE/UFRJ, Grupo Moeda e Sistema Financeiro, mimeo. Publicado em Banca Nazionale del Lavoro Quarterly Review, v. 53, n. 213, p. 135-170, 2000.

. The Recent Expansion of Foreign Banks in Brazil: First Results. IE/UFRJ, Grupo $\overline{\text { Moeda }}$ e Sistema Financeiro, mimeo. Publicado em Latin American Business Review, v. 3, n. 4, p. 93-119, 2002.

. Investimento, Poupança e Financiamento: Financiado o Crescimento com Inclusão Social. IE/UFRJ, Grupo Moeda e Sistema Financeiro, mimeo, 2005. Disponível em $<$ www.ie.ufrj.br/moeda $>$.

CERQUEIRA, D. R. C. Créditos e Inadimplência no Sistema Financeiro Nacional: Evolução Recente. IPEA, Boletim de Conjuntura, n. 42, p. 43-47, Jul. 1998.

CHICK, V.; DOW, S. Monetary policy with Endogenous Money and Liquidity Preference: A Nondualistic Treatment. Journal of Post Keynesian Economics, v. 24, n. 4, p. 587-607, Summer 2002.

CINTRA, M. A. M. A Reestruturação Patrimonial do Sistema Bancário Brasileiro e os Ciclos de Crédito entre 1995 e 2005. IE/UNICAMP, Política Econômica em Foco, n. 7, mimeo, abril 2006.

DAGES, B. G.; GOLDBERG, L.; KINNEY, D. Foreign and Domestic Bank Participation in Emerging Markets: Lessons from Mexico and Argentina. Federal Reserve Bank of New York Economic Policy Review, v. 6, n. 3, p. 17-36, Sep. 2000.

DE PAULA, L. F. R.; MARQUES, M. B. L. Tendências Recentes da Consolidação Bancária no Brasil. Análise Econômica, v. 24, n. 45, p. 235-263, Mar. 2006. 
DE PAULA, L. F. R.; ALVES JR, A. J.; MARQUES, M. B. L. Ajuste Patrimonial e Padrão de Rentabilidade dos Bancos Privados no Brasil durante o Plano Real (1994/98). Estudos Econômicos, São Paulo, v. 31, n. 2, p. 285-319, Abr./Jun. 2001.

DYMSKI, G. A. Credit Rationing and Financial Exclusion in the Age of Globalization. University of California Riverside, mimeo, March 2004.

FARIA JR, J. A.; DE PAULA, L. F. R.; MARINHO, A. Eficiência do Setor Bancário Brasileiro: A Experiência Recente das Fusões e Aquisições In: De Paula, L. F. R.; Oreiro, J. L. (Orgs.). Sistema Financeiro: Uma Análise do Setor Bancário Brasileiro. Rio de Janeiro: Campus-Elsevier, p. 125-154, 2007.

GREENE, W. H. Econometric Analysis. 5a edição. New Jersey: Pearson Education, 2003.

GUIMARÃES, P. How Does Foreign Entry Affect the Domestic Banking Market? The Brazilian Case. Latin American Business Review, v. 3, n. 4, p. 121-140, 2002.

GUJARATI, D. M. Econometria Básica. 3a edição. São Paulo: Pearson Education, 2000.

HSIAO, C. Analysis of Panel Data. 2a edição. Cambridge: Cambridge University Press, 2003.

LEVINE, R. Finance and Growth: Theory and Evidence. NBER Working Paper, n. 10.766, mimeo, Sep. 2004.

MARQUES, M. B. L.; DE PAULA, L. F. R. Tendências Recentes da Consolidação Bancária no mundo e no Brasil. Anais do IX Encontro Nacional de Economia Política, Uberlândia, mimeo, 2004.

NAKANE, M. I. A Test of Competition in Brazilian Banking. Banco Central do Brasil Working Paper Series, n. 12, March 2001.

SOARES, R. P. Evolução do Crédito de 1994 a 1999: Uma Explicação. Textos para Discussão IPEA, n. 808, julho 2001.

STOCK, J. H.; WATSON, M. W. Econometria. São Paulo: Person Education do Brasil, 2004.

VASCONCELOS, M. R.; FUCIDJI, J. R. Uma Avaliação dos Efeitos da Entrada de Bancos Estrangeiros no Setor Bancário Brasileiro. Análise Econômica, ano 21, n. 39, p. 163-188, Mar. 2003.

VASCONCELOS, M. R.; SCORZAFAVE, L. G.; FUCIDJI, J. R.; ASSIS, D. L. O Todo e as Partes: uma Análise da Desigualdade de Crédito entre os Estados Brasileiros e os Determinantes do Crédito Bancário com a Aplicação de Dados em Painel. Economia e Sociedade, n. 22, p. 123-149, Jan./Jun. 2004.

WRAY, L. R. Política Monetária: Metas de Taxas de Juros e a Natureza Não-Discricionária das Reservas. Capítulo 5. In: Trabalho e moeda hoje: a chave para o pleno emprego e a estabilidade de preços. Rio de Janeiro: Contraponto/Editora da UFRJ, p. 117-143, 2003.

YILDIRIM, H. S.; PHILIPPATOS, G. C. Restructuring, Consolidation and Competition in Latin American Banking Markets. Journal of Banking and Finance, v. 31, n. 3, p. 629-639, March 2007. 


\section{Anexo}

Os testes de endogeneidade são apresentados na tabela a seguir, respectivamente, para as variáveis DV, IB e T. Os resíduos das regressões auxiliares (Resid1, Resid2, Resid3) foram obtidos com as variáveis com suspeita de endogeneidade como dependentes.

Tabela A1

\begin{tabular}{|c|c|c|c|}
\hline \multicolumn{4}{|c|}{$\begin{array}{l}\text { Testes de Endogeneidade } \\
\text { (Variável dependente }=V \text { ) }\end{array}$} \\
\hline & (1) & (2) & (3) \\
\hline $\mathrm{C}$ & 8,27 & $-8,65 * *$ & $-21,38 * * *$ \\
\hline DV & 0,11 & 0,01 & $-0,01$ \\
\hline GA & $0,79 * * *$ & 0,30 & $0,85 * * *$ \\
\hline IB & 0,29 & $-0,26$ & $0,36 * *$ \\
\hline $\mathrm{T}$ & $-0,15$ & $-0,25 * *$ & 0,09 \\
\hline Selic & $-0,13$ & 0,03 & $0,32 * *$ \\
\hline PIB & 0,39 & $2,03 * * *$ & $2,64 * * *$ \\
\hline Resid1 & $-0,05$ & & \\
\hline Resid2 & & $-0,02$ & \\
\hline Resid3 & & & $-0,03$ \\
\hline $\mathrm{R}^{2}$ & 0,9723 & 0,9757 & 0,9632 \\
\hline $\mathrm{R}^{2}$ Ajustado & 0,9681 & 0,9720 & 0,9577 \\
\hline $\mathrm{F}$ & 229,34 & 263,61 & 176,13 \\
\hline Prob(F) & 0,00 & 0,00 & 0,00 \\
\hline CIA & $-0,6573$ & $-0,7807$ & $-0,3847$ \\
\hline CIS & $-0,2448$ & $-0,3701$ & 0,0203 \\
\hline
\end{tabular}

Os sinais esperados das variáveis estão entre parênteses.

* indica significância a 10\%;

** indica significância a 5\%;

*** indica significância a 1\%.

Recebido em: 02/10/2008.

Aceito em: 11/11/2008. 